\title{
Promises to clean up industry fail to convince
}

\section{SYDNEY}

Some of the world's biggest polluters and energy consumers met last week under a scheme trumpeted by organizers as a "complement" to the Kyoto Protocol. Members of the Asia-Pacific Partnership (AP6) on Clean Development and Climate promised to provide practical solutions to climate change, by driving industrial partnerships and encouraging new, cleaner technologies. But withvoluntary participation, no emissions targets, nodeadlines and little new money, environmentalgroups are somewhat sceptical.Can indus try really be counted on tocleanup its act?

The inaugural meeting of the AP6, held in Sydney on 11 and 12 January, was attended by senior government and business representatives from Australia, China, India, Japan, South Korea and the UnitedStates - countries that together are responsible for around half of the world's greenhouse-gasemissions.

Butenvironmental groups are not impressed by AP6's unwillingness to set targets or adopt carbon trading. "It's incredibly disappointing that AP6 isn't prepared to put in place financialmechanisms toreward those whoinvest in cleaner energy and penalize those who don't," says Erwin Jackson of the Australian Conservation Foundation, basedin Melbourne.

Many industry representatives see it differently. "I don't think the first step should be to create an unequal playing field by putting carbon-trading mechanisms in one place and not in another," counters Oscar Groeneveld, chief executive of the Rio Tinto Aluminium group.

So the meeting focusedinstead on garnering a range of softer commitmentsfromindustryto share knowledge, develop technology and improve operating practices. The main achievement was the establishment of eight government-industry task forces to

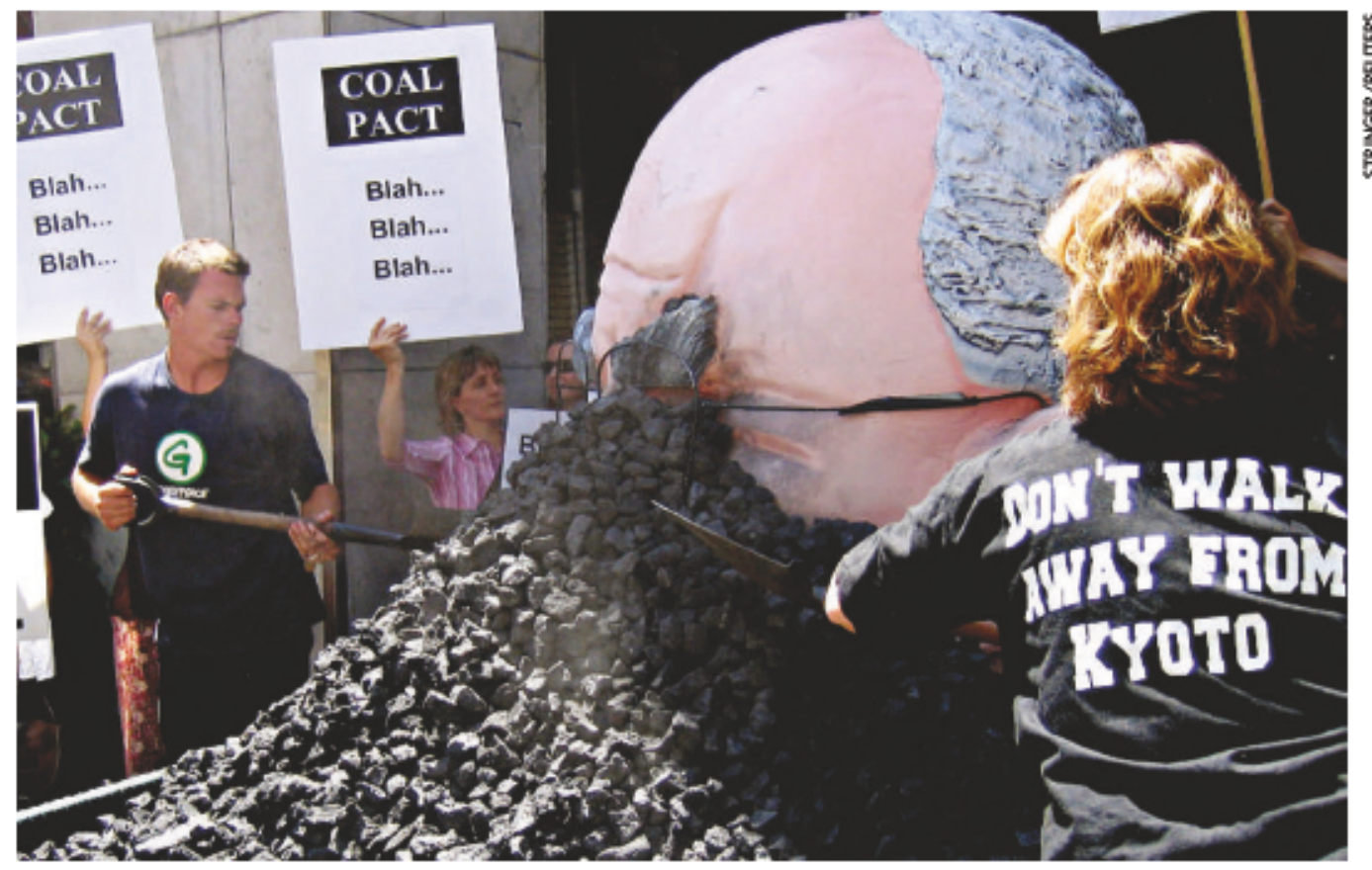

Protesters express scepticism while representatives of the world's top pollutersmeet in Sydney to consider cleaner ways.

focus on power generation; coal mining; building and appliances; the production of cleaner fossil energy, renewable energy, steel, aluminium and cement. The groups will meet separately to formulate priorities, action plans and progress indicators, before reporting back to the next AP6 gathering probably in January nextyear.

\section{Supporters insist}

this will bring significant gains.

"There are some low-hanging fruit," says Groeneveld. "If we lift the performance of the bottom half of class', we can improve the whole industry and substantially reduce emissions."

Both the Australian and US governments committed new funds: AU $\$ 100$ million (US\$75.5 million) over five years, and a one-off US\$52 million respectively. But industry is largely expected to foot the bill. Details of exactly what will change are lacking, however, as industry groups say they will essentially continue their ongoing investment into research and development.
Advocates of AP6, including US Secretary of Energy Samuel Bodman, point to the aluminium ind us try as evidence that the voluntary approach can work. The ind us try seta series of "voluntary objectives" in 2003, such as reducing perfluorocarbon ( $\mathrm{PFC}$ ) emissions, which Groeneveld claims have been "collectively reduced by $75 \%$ since $1990^{\prime \prime}$.

That doesn't impress the critics. "There is not much new money on the table and we already have a large number of technology-transfer mechanisms in place," says lain McGill, an engineer who is researching energy markets at the University of New South Wales in Sydney.

"You have to question how significant the initiative is," says McGill. He and others are sceptical that things will change fast enough without gover nment regulation. "Even if youdevelop the most whizbang technologies, you still have to get them in place," he says. "It might happen - but you wouldn't want to bet the climate on it."

"The scale of the climate changes being projected for $\mathbf{2 0 5 0}$ are so substantial that to say, "there will be a technological fix' is inadequate," adds Andy Pitman, a climate scientistat Macquarie University in Sydney. "As scientists, we haven't managed to get across the urgency of the problem."

Even the petroleum giant $B P$ seems unconvinced by the voluntary approach. "Low-emission technologies are available now," points outa spokesman for BP Australia. But to ensure their uptake "market pull is essential," he says, adding that to "reduce the costs of low-carbontechnologies to parity with conventional power sources".

Perhaps this incentive, if unspoken, was felt at the AP6 meeting. "If industry doesn't act responsibly, governments will have to intervene and regulate," says John White, chairman of the Perth-based comp any Global Renewables. "No one wants to talk about it, but that was definitely a take-homemessage."

Carina Dennis 